\title{
Effects of $\alpha$-crystallin gene knockout on zebrafish lens development
}

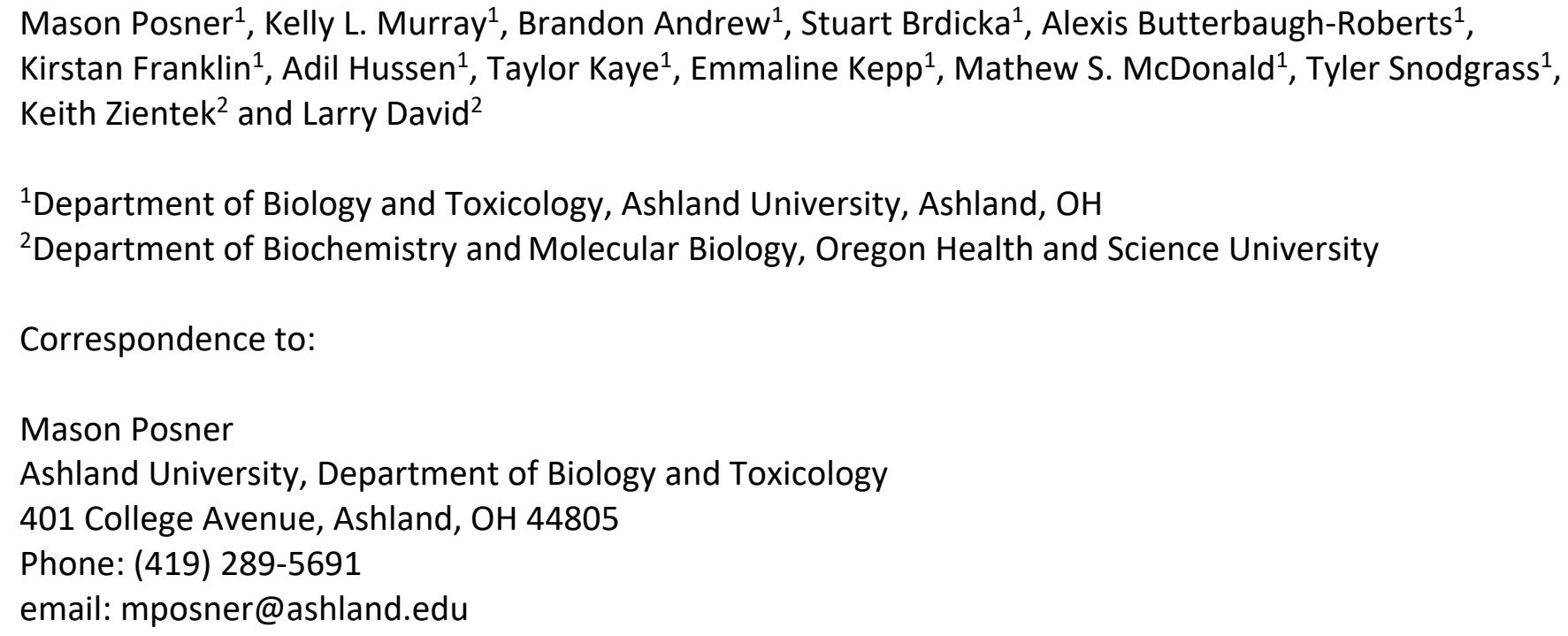

\section{Abstract}

The $\alpha$-crystallin small heat shock proteins contribute to the transparency and refractive properties of the vertebrate eye lens and prevent the protein aggregation that would otherwise produce lens cataract, the leading cause of human blindness. There are conflicting data in the literature as to what role the $\alpha$-crystallins may play in early lens development. In this study we used CRISPR gene editing to produce zebrafish lines with null mutations for each of the three $\alpha$-crystallin genes (cryaa, cryaba and $c r y a b b)$. Absence of protein was confirmed by mass spectrometry and lens phenotypes were assessed with differential interference contrast microscopy and histology. Loss of $\alpha$ A-crystallin produced a variety of lens defects with varying severity in larval lenses at 3 and $4 \mathrm{dpf}$, but little significant change in normal fiber cell denucleation. Loss of either $\alpha \mathrm{Ba}$ - or $\alpha \mathrm{Bb}$-crystallin produced no significant lens defects. Mutation of each $\alpha$-crystallin gene did not alter the expression levels of the remaining two, suggesting a lack of genetic compensation. These data confirm a developmental role for $\alpha A$-crystallin in lens development, but the range of phenotype severity suggests its loss simply increases the chance for defect, and that the protein is not essential. Our finding that cryaba and cryabb null mutants lack noticeable lens defects is congruent with insignificant transcript levels in lens epithelial and fiber cells. Future experiments can explore the molecular consequences of cryaa mutation and causes of lens defects in this null mutant, as well as the roles of other genes in lens development and function. 


\section{Introduction}

Alpha crystallins are small heat shock proteins that contribute to the high protein density that produces the refractive power of the vertebrate eye lens (Horwitz, 1992). Because of their ability to bind denaturing proteins and block aggregation, $\alpha$-crystallins are thought to prevent lens cataract, the leading cause of human blindness worldwide. Their expression in tissues outside the eye, especially the broadly expressed $\alpha B$-crystallin, also suggests that they may play diverse physiological roles (Srinivasan, Nagineni \& Bhat, 1992). Numerous studies link $\alpha B$-crystallin to the physiology and disease of muscular and nervous tissue (Bova et al., 1999).

Zebrafish have been a valuable model for investigating lens crystallin function. Zebrafish and human lenses are made of similar proteins, and the mechanisms underlying their development are conserved (Posner et al., 2008; Greiling, Aose \& Clark, 2010). The production of large numbers of transparent embryos and the ease with which zebrafish can be genetically manipulated makes them a good tool for examining crystallin function. The presence of two $\alpha B$-crystallin paralog genes in zebrafish provides an opportunity to dissect the roles of this multi-functional single mammalian protein (Smith et al., 2006). The accessibility of early-stage embryos and fast development times make zebrafish ideal for studying the roles of $\alpha$-crystallins in early lens development. These studies in zebrafish are more convenient and much less costly than in mammalian systems such as mouse.

Various genetic knockout and translation blocking techniques have been used to investigate the impacts of $\alpha$-crystallin loss on zebrafish lens development. These experiments showed that loss of any of the three $\alpha$-crystallin genes produced lens defects in 3 and 4 day old fish (Zou et al., 2015; Mishra et al., 2018). This result differed from work in mouse, which showed that while the loss of $\alpha A$-crystallin led to reduced lens size and early cataract development, the loss of $\alpha \mathrm{B}$-crystallin did not produce a lens phenotype, although heart defects were found (Brady et al., 1997, 2001). Furthermore, our recent analysis of zebrafish gene expression at single cell resolution indicated that neither of the two $\alpha \mathrm{B}$ crystallin genes were expressed in the lens at significant levels through five days of development (Farnsworth, Posner \& Miller, 2021). Therefore, there seems to be conflicting reports on what role, if any, $\alpha B$-crystallins play in early lens development.

In this present study we examine the larval lens in newly generated knockout lines for all three zebrafish $\alpha$-crystallin genes. The resulting data address open questions about what effect, if any, the loss of either $\alpha \mathrm{B}$-crystallin protein will have on lens development. We also provide a more detailed analysis of lens phenotypes after $\alpha$ A-crystallin loss and compare several approaches for producing gene knockouts using CRISPR editing. This data analysis can provide a set of best practices for future studies of lens gene function. 


\section{Materials and Methods}

\section{Fish maintenance}

The use of zebrafish in this study was approved by Ashland University's Animal Use and Care Committee (approval \#MP 2019-1). Fish were maintained on a recirculating aquarium system at approximately $28^{\circ} \mathrm{C}$ with a $14: 10$ light and dark cycle with daily water changes. Juveniles and adults were fed twice each day with a combination of dry flake food and live Artemia cultures. Adults were bred in separate false bottom tanks to collect fertilized eggs, which were incubated in petri dishes with system water at $28^{\circ} \mathrm{C}$. Resulting larvae that were to be raised to adulthood were fed a liquid slurry of ground zooplankton and green algae until large enough to eat flake food and Artemia.

\section{Guide RNA design, production and injection}

Target regions for the guide RNA (gRNA) used in single and double injections were identified using the CRISPR design tool in the Benchling digital notebook system (www.benchling.com). The target regions for the four-gRNA mix used with cryaa were identified by Wu et al. 2018 (Wu et al., 2018). Sequences for all gRNA primers are shown in Supplemental Table 1. Guide RNAs were produced using a PCR-based plasmid-free approach that annealed and elongated a universal scaffold primer with one, two or four additional primers containing the sequence of the target region. Equimolar amounts of universal scaffold primer and target region primers were used with Q5 DNA polymerase (NEB). Cycling parameters included a touchdown PCR protocol: initial $94^{\circ} \mathrm{C}$ denaturation for $5 \mathrm{~min}$; cycle parameters: $94^{\circ} \mathrm{C}$ for $20 \mathrm{sec}, 65^{\circ}$ for $20 \mathrm{sec}, 68^{\circ} \mathrm{C}$ for $15 \mathrm{sec}(13$ additional cycles with extension temperature reduced $0.5^{\circ} \mathrm{C}$ per cycle); 30 additional cycles of: $94^{\circ} \mathrm{C}$ for $20 \mathrm{sec}, 58^{\circ} \mathrm{C}$ for $20 \mathrm{sec}, 68^{\circ} \mathrm{C}$ for $15 \mathrm{sec}$; final extension $68^{\circ} \mathrm{C}$ for 5 minutes. Resulting PCR product was purified with the Monarch PCR and DNA Cleanup Kit (NEB) with elution in 20 microliters nuclease free water. Up to $1000 \mathrm{ng}$ of purified PCR product was used with the HighScribe $T 7$ kit (NEB) and incubated overnight at $37^{\circ} \mathrm{C}$ and reaction was purified with the Monarch RNA Cleanup Kit (500 micrograms) with elution in $50 \mu$ l nuclease free water (NEB). Quality of the gRNA prep was confirmed by agarose gel.

Each injection mix contained $250 \mathrm{ng} / \mu \mathrm{l}$ total of the purified gRNAs and $500 \mathrm{ng} / \mu \mathrm{l}$ of recombinant Cas 9 protein (PNA Bio) with $0.2 \%$ phenol red in nuclease free water. One nanoliter of mix was microinjected with a single 20 millisecond pulse into the cytoplasm of each zebrafish zygote using a Harvard Apparatus PL-90 picoinjector (Holliston, MA).

\section{Identification of null lines}

Embryos injected with single or double gRNAs were genotyped after at least two months of age. Fish were anesthetized in $0.016 \%$ tricaine methane sulfonate (MS-222) resuspended in trisma base and the posterior edge of the fin was removed with scissors. Fish were kept separated for recovery and while genotyping took place. Genomic DNA was collected from each fin clip using the Monarch Genomic DNA Purification kit (New England Biolabs) and amplified with PCR primers that flanked the gRNA targeted region using OneTaq $2 X$ Master Mix (NEB). The recommended PCR protocol was followed, with appropriate annealing temperatures determined experimentally. All primers and annealing temperatures are shown in Supplemental Table 1. Amplified genomic DNA targeted with one gRNA was sequenced to determine whether more than one sequence was apparent beginning at the target 
area. Mutated genomic regions targeted with two gRNAs could be identified directly by the size of the resulting PCR product.

Fish resulting from injected zygotes (founder fish) determined through fin clipping to contain mutant alleles were outcrossed to wildtype fish. Ten resulting embryos were combined and homogenized to purify genomic DNA and the targeted gene region amplified to determine if the parent founder fish had passed on mutant alleles to offspring. If offspring were found to be heterozygous for a gene mutation, larvae were raised another two months for fin clipping. For single gRNA injected fish, sequencing of the heterozygotes was done to determine if the resulting mutation would cause a frame shift and early stop codon. Multiple heterozygotes with the same identified frame shift mutation were incrossed to produce null individuals that were then used to produce null lines. For double gRNA injected embryos, sequencing was used to identify heterozygotes with the same deletion, which were then incrossed to generate a null line.

\section{Proteomic assessment of knockout fish}

A detailed protocol outlining the sample preparation of zebrafish lenses to detect the presence of $\alpha$ crystallins was previously published (Posner et al., 2017). Briefly, $50 \mu \mathrm{g}$ portions of protein derived from either one or two dissected lenses were digested overnight with trypsin in the presence of ProteaseMax ${ }^{\mathrm{TM}}$ detergent as recommended by the manufacturer (ProMega, Madison, WI, USA). One $\mu \mathrm{g}$ of each tryptic digest was then injected at $10 \mu \mathrm{l} / \mathrm{min}$ onto a Symmetry C18 peptide trap (Waters Corporation, Milford, MA, USA) for 0-5 min using a 98\% water, 2\% acetonitrile (ACN), 0.1\% formic acid mobile phase, then switched onto a $75 \mu \mathrm{m}$ x $250 \mathrm{~mm}$ NanoAcquity BEH $130 \mathrm{C} 18$ column (Waters Corporation) using mobile phases water $(A)$ and $A C N(B)$ each containing $0.1 \%$ formic acid, and peptides separated using a 7.5-30\% ACN over 5-35 min, 30-98\% from 35-36 min, 98\% ACN from 36-41 min, 98-2\% ACN from 41-42 min, and 2\% ACN from 41-60 min at a $300 \mathrm{~nL} / \mathrm{min}$ flow rate. Eluent was analyzed using a Q-Exactive HF mass spectrometer using electrospray ionization with a Nano Flex Ion Spray Source fitted with a $20 \mu \mathrm{m}$ stainless steel nano-bore emitter spray tip and $1.0 \mathrm{kV}$ source voltage (ThermoFisher Scientific, San Jose, CA, USA). Xcalibur version 4.0 was used to control the system. Survey mass spectra were acquired over m/z 400-1050 at 120,000 resolution, automatic gain control (AGC) target $3 \times 10^{6}$, maximum ion time (MIT) of $200 \mathrm{~ms}$, profile mode, and lock mass correction using $\mathrm{m} / \mathrm{z}=445.12002$ and 391.28429 polysiloxane ions. Parallel reaction monitoring (PRM) was also performed using a list of 39 precursors from $\alpha \mathrm{A}, \alpha \mathrm{B}$, and $\alpha \mathrm{Bb}$ zebrafish crystallin peptides, as well as $\alpha$-spectrin to assess column loading. A loop count was set to repeat precursor scans every 10 PRM scans. PRM scans were performed at 15,000 resolution, AGC target $2 \times 10^{5}$, MIT of 100 ms, normalized collision energy of 27, and isolation width of $2 \mathrm{~m} / \mathrm{z}$. Results were processed using Skyline Software version 21.1.0.278 (Pino et al., 2020) using a previously constructed spectral library generated by a data-dependent MS/MS experiment from a wild type zebrafish lens digest (Posner et al., 2017). The relative abundance was determined by comparison of 4 peptides with the strongest intensities from each of the proteins. (Peptides and precursor masses listed in Supplemental Table 2).

\section{Phenotype assessment}

Embryos produced by incrossing the null lines were treated in $0.2 \mathrm{mM}$ PTU in system water between 6 and 20 hours post fertilization to maintain transparency. The gross anatomy of each larva was imaged at 45 total magnification on a dissecting microscope while one of their lenses was imaged at 200X total 
magnification using differential interference microscopy on an Olympus IX71 microscope. Images were taken with SPOT cameras and were cropped and oriented using Image $(\mathrm{NIH})$. Lens diameters were measured in ImageJ with a line spanning the lens equator, which differs from the anterior-posterior dimension (Wang et al., 2020). Body lengths were measured from the tip of the snout to the end of the axial skeleton. Any statistically significant differences in measurements between genotypes was calculated using the anova and TukeyHSD functions in R (R Core Team, 2021) within RStudio (RSTudio Team, 2020).

Larvae were anesthetized and then transferred to $4 \%$ paraformaldehyde with $5 \%$ sucrose for storage at $4^{\circ} \mathrm{C}$ until cryosectioning and DAPI staining to observe the presence of lens cell nuclei. The sectioning procedure has been previously reported (Posner et al., 2013). Resulting slides with 10 micron lens sections were mounted using Vectashield Antifade Mounting Medium with DAPI (Vector Laboratories) and imaged on an Olympus IX71 microscope. DAPI intensity across the diameter of the lens was measured using the Concentric Circles plugin for ImageJ. An oval was drawn matching lens shape and 10 concentric circles were used to quantify average pixel intensity along the perimeter of each circle. Any statistically significant differences in average pixel intensity between genotypes at each circle was calculated with a Mann-Whitney $U$ test in R. All scripts and data used for this and other analyses in this study can be found in this repository on GitHub: github.com/masonfromohio/alpha-crystallin-CRISPRRscripts

\section{Quantitative PCR analysis of alpha crystallin expression}

The qPCR methods were designed to meet MIQE guidelines (Bustin et al., 2009) and followed methods previously described (Posner et al., 2017). Larvae were collected at $7 \mathrm{dpf}$ and stored in RNAlater (Thermo) at $4^{\circ} \mathrm{C}$ for up to one month until used for purification of total RNA with the Monarch Total RNA Miniprep Kit (NEB). Five larvae were used for each RNA purification and homogenized in DNA/RNA protection buffer with a glass homogenizer prior to proteinase $\mathrm{K}$ digestion, following the kit protocol. DNase treatment was performed in the RNA purification column, with a final elution in $50 \mu$ of nuclease free water. The concentration of collected RNA was measured in a Nanodrop One (Thermo Fisher). The ProtoScript II First Strand cDNA Synthesis Kit (NEB) was used with 600 ng of total RNA from each sample with the $d(T) 23$ VN primer using the standard protocol and -RT controls were included.

Luna Universal qPCR Master Mix (NEB) was used to amplify $1.5 \mu$ l of each cDNA sample in a $20 \mu$ total reaction using the manufacturer's standard protocol on an Applied Biosystems StepOne Real-Time PCR System (Thermo). Three technical replicates were used for each cDNA sample, while two technical replicates were used with all -RT and non template controls (water). Two endogenous control primer sets were included ( $r p / 13 a$ and $e f 1 a$ ). All primer sequences and previously calculated efficiencies are shown in Table 2 of (Posner et al., 2017). Reactions included primers at a final concentration of $250 \mathrm{~nm}$ with the following parameters: hold at $95^{\circ} \mathrm{C}$ for $1 \mathrm{~min} ; 40$ cycles of $95^{\circ} \mathrm{C}$ for $15 \mathrm{~s}$ and $60^{\circ} \mathrm{C}$ for $30 \mathrm{~s}$; fast ramp setting. Melt curve analysis was used to confirm that single products were produced, and amplification products had previously been sequenced to confirm their expected identity (Posner et al., 2017). Analysis of resulting Cq values was identical to the process previously reported (Posner et al., 2017). 


\section{Results}

Disruption of cryaa produced several types of lens defects that ranged in severity

We used two approaches to mutate the zebrafish cryaa gene to prevent the production of $\alpha \mathrm{A}$ crystallin protein. First, we injected a single guide RNA (gRNA) to produce frame shift mutations and an early stop codon (Fig 1A). This approach successfully produced a 5 base pair deletion and early stop codon after the leucine residue in position 27 (Fig 1B). Mass spectrometry confirmed that this mutant prevented the production of any measurable $\alpha A$-crystallin protein, as shown by the absence of $\alpha A$ crystallin peptide 52-65 in the cryaa -/- lens (Fig 1C, right). Three additional $\alpha A$-crystallin peptides that were monitored were also missing in cryaa -/- lens (Supplemental Fig. 3B-D). Differential interference contrast (DIC) microscopy of anesthetized and PTU treated larvae at 3 days post fertilization (dpf) showed that cryaa homozygous null fish (cryaa ${ }^{-/}$) had lens irregularities. These phenotypes included a central roughness and disorganization of central fiber cells compared to wildtype controls (Fig $1 \mathrm{D}-\mathrm{F}$ ). Because this original cryaa null line stopped breeding, we produced a second null line by using two gRNAs to produce an 863 bp deletion that removed a portion of the cryaa promoter and start codon region (Fig 2A). This approach made it simpler to identify mutants by PCR (Fig 2B) and reduced the potential for genetic compensation due to mutant mRNA degradation, as no truncated mRNA would be produced (El-Brolosy et al., 2019). The resulting cryaa null line bred well and all further data presented are from these fish.

A significant proportion of cryaa null larvae had lenses that appeared similar to those of wildtype fish (Fig 2C). Others showed phenotypes that we classified into five categories. Some lenses had central roughness that appeared as many small darker spots in the region of the primary fiber cells (Fig 2D). Some lenses contained elongated roughened areas that appeared to trace the edges of fiber cell boundaries (Fig $2 \mathrm{D}$ and $\mathrm{E}$, black arrows). We also found lenses with a disorganization of central fiber cells (Fig $2 \mathrm{E}$ and F). These lenses did not show the regular circular rings of central fiber cells. Some lenses showed more severe boundaries between fiber cells, possibly at the interface between the lens nucleus and cortex (Fig 2G, black arrows), and some lenses exhibited large pits (Fig 2H).

Frame shift mutations of the two paralogs for zebrafish $\alpha \mathrm{B}$-crystallin genes did not produce noticeable lens defects

Single gRNAs were designed to target exon 1 in both the cryaba and cryabb genes (Fig 3). Injected embryos were raised and those with mutations leading to frameshifts and early stop codons were identified. A single basepair deletion in cryaba led to altered amino acid sequence after residue 14 and a stop codon at residue 65 (Fig 3B). Mass spectrometry indicated that lenses from cryaba homozygous mutant adults expressed no detectable $\alpha$ Ba-crystallin, as evidenced by missing tryptic peptide 11-21 in the mutant lens (Fig 3C, right). An 8 bp deletion in cryabb produced altered amino acids after residue 9 and a stop codon at residue 26 (Fig 3D \& E). Digests of adult cryabb homozygous null fish lens had undetectable levels of peptide 45-57 (Fig 3F, right). While minor amounts of other cryaba and cryabb peptides from null fish lenses were sometimes detected, these were attributed to carry-over on the liquid chromatography column from prior analysis of wildtype lenses (Supplemental Fig. 1: G-I and J-L). 
The prevalence of lens defects in larvae generated by our cryaa, cryaba and cryabb null lines was quantified at 3 and $4 \mathrm{dpf}$ to assess the impacts of loss of each $\alpha$-crystallin on lens development (Fig 4). The least common defect, but a characteristic one in cryaa null larvae, was the presence of visual roughness in the center of the lens. A more common defect, but most prevalent after cryaa loss, was a defect seen in peripheral fiber cells that appeared as a widening of the normally tight boundary between these cells. This peripheral fiber cell defect was more common at $4 \mathrm{dpf}$ in both cryaa null larvae and larvae directly observed after injecting embryos with a four-guide RNA mix (pgRNA). Two other defect types: a disorganization of central lens and severe boundaries between fiber cells, all occurred in some wildtype lenses, but were more common in cryaa homozygous null larvae. Pitting in the lens was the most common defect seen in wildtype larvae and not noticeably increased after cryaa loss. All defect types were seen in cryaba and/or cryabb null larvae, but at much reduced proportions compared to cryaa null larvae, and at levels similar to wildtype larvae. When pooling all defects together, over $60 \%$ of cryaa null larvae showed some defect, whereas cryaba and cryabb null larvae showed below $20 \%$, similar to wildtype larvae.

All larvae used to assess lens phenotype were measured to record body length and lens diameter at 3 and $4 \mathrm{dpf}$ (Fig 5). These data show an increase in body length from 3 to $4 \mathrm{dpf}$ in all genotypes, as would be expected. Body length was more varied between two independent wildtype samples than between wildtype and null samples, suggesting that gene knockout did not alter overall fish growth rate compared to wildtypes. There appeared to be little to no difference in lens diameter between 3 and 4 dpf samples, which produced a decrease in the lens to body length ratio between those two timepoints for all genotypes. The only measurement that was statistically different from both wildtype samples was the lens diameter of cryabb knockout larvae at $4 \mathrm{dpf}$.

\section{Loss of $\alpha$-crystallins did not disrupt fiber cell denucleation} Fiber cells of the zebrafish lens elongate and lose their nuclei between 2 and $3 \mathrm{dpf}$. We examined lenses histologically at 3 and $4 \mathrm{dpf}$ to determine if this process was altered by loss of each $\alpha$-crystallin (Fig 6). Wildtype lenses showed that the details of this process can vary, but that the majority of lenses have cleared all nuclei from central fiber cells, leaving elongated nuclei at the posterior margin (Fig 6A, white boxes). We consistently found two posterior zones of extended fiber cells bordering a denucleated space between them (Fig 6A, asterisk), with what appeared to be a single layer of nuclei adjacent to the retinal neurons. Lenses contained rings of DAPI staining just anterior to the remaining, elongated fiber cells and extending forward with a gap between the anterior margin and the epithelial fiber cells (Fig 6A, white arrows). The posterior-most gap between elongated fiber cells was a good indicator that sections imaged were through the equator of the lens. Elongated fiber cell nuclei in wildtype lenses ranged from flat to wavy, and occasionally retained an oval shape (Fig 6C, white arrow). At $4 \mathrm{dpf}$ the posterior fiber cell nuclei stacks appeared thinner and the DAPI rings less common.

The lenses of cryaa null $3 \mathrm{dpf}$ larvae also varied in phenotype. However, more abnormal phenotypes were seen. A small number of cryaa null lenses retained fiber cell nuclei deep to the central DAPI staining ring (Fig $6 \mathrm{I}$ and J) or on the ring itself (Fig $6 \mathrm{H}$ ). Quantitation of pixel intensity also showed that some cryaa null larval lenses had higher amounts of DAPI staining material in the deeper parts of the cortex and lens nucleus, but the mean pixel intensity did not differ statistically from wildtype larvae (Fig $6 \mathrm{~N}$ ). None of the $4 \mathrm{dpf}$ cryaa null larvae examined retained abnormal fiber cell nuclei. None of the 
cryaba or cryabb $3 \mathrm{dpf}$ larvae examined showed retained fiber cell nuclei within the central lens (Supplemental Figure 2). However, some lenses did appear to have thicker fiber cell nuclei stacks, and possibly more oval nuclei, although these features were also seen in some wildtype lenses as described above.

CRISPR deletion of each $\alpha$-crystallin gene did not alter expression of the other two

Quantitative PCR (qPCR) was used to measure $\alpha$-crystallin gene expression levels in wildtype and our knockout lines. This allowed us to determine if mutation led to a decrease in mRNA levels for the damaged gene or changes in expression of the other $\alpha$-crystallin genes. Whole larvae were assessed at $7 \mathrm{dpf}$ as earlier work showed low levels of cryaba and cryabb expression through 4 and $5 \mathrm{dpf}$, respectively (Posner et al., 2017), and almost no expression in the lens (Farnsworth, Posner \& Miller, 2021). We found reduced levels of cryaa mRNA in $7 \mathrm{dpf}$ homozygous null mutants with the large deletion removing the proximal promoter and start codon (Fig 7A). Expression levels of cryaa did not increase in cryaba and cryabb null larvae compared to wildtype larvae (Fig 7A). The cryaba and cryabb null lines were not produced by deleting the promoter and start codon, but instead were produced with a single gRNA producing frame shift mutations and early stop codons (Fig 3). cryaba mRNA levels were not different in the cryaba null larvae compared to wildtype, nor were they increased in the other null lines (Fig 7B). Messenger RNA for cryabb was reduced in cryabb null larvae compared to other mutant lines (Fig 7C). While delta Cq values for cryabb mRNA in cryabb null mutants were all lower than wildtype larvae, this difference was not statistically significant. Messenger RNA levels for $c r y a b b$ were not statistically significantly increased in cryaa or cryaba null mutants compared to wildtype larvae.

\section{Discussion}

We produced mutant zebrafish lines lacking each of the three $\alpha$-crystallin proteins. Lack of $\alpha A$ crystallin caused a variety of visible lens defects in mutant larvae not seen, or present at lower frequency, in wildtype larvae. Lack of either $\alpha B$-crystallin did not cause an increase in lens abnormalities. Loss of $\alpha A$-crystallin did not alter overall lens growth, nor significantly disrupt the fiber cell denucleation important for lens development. Finally, none of the gene knockouts produced compensatory changes in mRNA levels of the others. These data suggest that loss of $\alpha A$-crystallin makes zebrafish lenses more susceptible to defects in development, but does not always trigger these defects. Loss of either cryaba nor cryabb produced no noticeable changes in lens development through four days of development.

Our observation of lens abnormalities in our CRISPR-produced cryaa null larvae matches previous work done with a TALEN-produced cryaa knockout line (Zou et al., 2015). Lens images from that study showed central roughness and pitting of the lens, but not the central disorganization, peripheral fiber cell defects or severe fiber cell boundaries that we found to be characteristic of cryaa null larvae. The proportion of null incross larvae with lens defects in the TALEN study was approximately $85 \%$, a bit more than our finding of $60 \%$. However, that study separated their phenotypes into "minor" and "major", with just over $40 \%$ of larvae with minor lens defects. Despite the different methods used to characterize lens defects in our present study and this past TALEN work, it seems that the observed 
penetrance of cryaa loss is comparable. It is notable that the effects of $\alpha A$-crystallin loss can range from no apparent defect in lens structure to a variety of defects that can occur singly or in combination. A similar range in lens effects was seen after CRISPR knockout of zebrafish aquaporin 0 paralogs, mipa and mipb (Vorontsova et al., 2018). Our results suggest that $\alpha A$-crystallin is not essential for proper lens development through 4 days post fertilization, but that its loss does predispose the lens to defect. The only other model species with an $\alpha A$-crystallin knockout line is the mouse (Brady et al., 1997). Due to the in utero development of the mouse, and its pigmentation, it was likely not feasible to make similar observations of lens development at comparable stages to this study. However, that study showed that cryaa null mice develop cataract by 7 weeks of age, indicating the protein's importance in lens biology. The impact of cryaa loss on zebrafish lens clarity as animals age can be addressed in the future using our validated lines.

The results of CRISPR null mutation, reported here, can be compared to prior knockdowns by morpholino injection. We previously reported a lack of lens defects in zebrafish larval lenses at $3 \mathrm{dpf}$ after using a morpholino to block the translation of $\alpha$ A-crystallin (Posner et al., 2013). Similar results were reported in a later study (Hinaux et al., 2014). Neither study imaged lenses using DIC microscopy, so it is possible that defects like those identified in this current study were missed. It is also possible that small amounts of $\alpha \mathrm{A}$-crystallin produced during those morpholino experiments were sufficient to prevent the defects found in this study.

Our data do not directly address mechanisms behind the lens defects seen in our cryaa null lenses. Histology and DAPI staining of 3 and $4 \mathrm{dpf}$ larvae indicate that while there may be some delay in fiber cell denucleation in cryaa null lenses, this was found in a small proportion of lenses at $3 \mathrm{dpf}$ and gone by $4 \mathrm{dpf}$. Because $\alpha \mathrm{A}$-crystallin has documented functions as an anti-aggregation chaperone that can buffer the effects of stress in the lens (Horwitz, 1992), it is possible that its loss may make the lens more susceptible to protein aggregation. This likely led to the cataract seen in cryaa null mouse lenses (Brady et al., 1997), and since zebrafish $\alpha$ A-crystallin has chaperone activity (Dahlman et al., 2005; Koteiche et al., 2015), aggregates in central fiber cells may lead to observed central roughness. This hypothesis could be tested by future proteomic analysis of insoluble protein. Other defects we observed hint at a breakdown in normal fiber cell arrangement. Under DIC imaging the fiber cell borders in the zebrafish lens are visible as regular concentric rings (Fig 1D). Our observation of central disorganization suggests defects in this cellular arrangement affecting central fiber cells. A separate defect produced short regions of expanded space between peripheral fiber cells, while least common were more severe, extended borders between fiber cells. These three anatomical defects were visually distinct, and may stem from different mechanistic defects in fiber cell interactions. It has been proposed that $\alpha A$-crystallin may play a direct role in fiber cell differentiation (Boyle \& Takemoto, 2000). While our cryaa null larvae did not show extended defects in fiber cell nucleus degradation, there may be other aspects of fiber cell differentiation impacted by $\alpha A$-crystallin loss.

Our finding that lens diameters in cryaa null lenses at 3 and $4 \mathrm{dpf}$ were similar to wildtype larvae matches results of a previous knockout study (Zou et al., 2015). Our cryaba and cryabb null larvae also appeared similar in body length and lens diameter to wildtype larvae. We included two separate samples of wildtype larvae to assess possible variation between breedings or different fish tanks with 
the same genotype. The statistically significant variation in body length between these two wildtype samples suggests that variation between groups can be high, and should be taken into account when looking for changes in lens growth resulting from gene knockout. The observation that lens diameter was essentially unchanged between 3 and $4 \mathrm{dpf}$, while body length increased, was unexpected considering that past studies have found linear relationships between lens diameter and body length, although these studies did not examine fish prior to $7 \mathrm{dpf}$ (Collery et al., 2014; Wang et al., 2020). It is possible that in these earlier stages body length and lens diameter growth are not parallel.

We found no evidence that mutation of either $\alpha \mathrm{B}$-crystallin gene in zebrafish caused abnormalities in lens development or structure. Neither our cryaba nor cryabb null mutant larvae showed any of the lens defects above levels seen in wildtype, with the exception of a few more larvae with peripheral fiber cell defects or severe fiber cell boundaries (Fig 4). This was in contrast to much higher proportions of all defects, except pitting, in cryaa null larvae. Fiber cell denucleation also appeared normal in both $\alpha \mathrm{B}$-crystallin mutant lines. The lack of developmental lens defects in these fish is consistent with knockout studies in mouse in which loss of the single $\alpha B$-crystallin gene had no effect on lens clarity through 39 weeks of age, although early developmental stages were not examined (Brady et al., 2001). However, previously published CRISPR mutants for cryaba and cryabb did produce lens defects at $4 \mathrm{dpf}$ in a large proportion of larvae (Mishra et al., 2018). In that study approximately $75 \%$ and $50 \%$ of cryaba and cryabb null larvae, respectively showed lens abnormalities. Defects were categorized as "minor" and "major" with little description of defect type. Two published images of lenses from a cryaba heterozygote cross show roughness or pitting as well as some gaps between fiber cells. Previous work by the same lab identified far more severe lens defects in zebrafish larvae after injection of translationblocking morpholinos targeting cryaba and cryabb (Zou et al., 2015). However, general gross defects in resulting larvae suggest general toxicity from the morpholinos and not a lens specific effect. In their more recent CRISPR lines there were no reported general larval defects, further suggesting that the morpholino-induced lens defects were not specifically due to the loss of $\alpha B$-crystallin proteins.

Existing data suggest that neither cryaba nor cryabb are significantly expressed in the zebrafish lens through $5 \mathrm{dpf}$, based on shotgun proteomics (Greiling, Houck \& Clark, 2009) and single cell RNA-Seq (Farnsworth, Posner \& Miller, 2021). These previous findings might explain the lack of noticeable early lens phenotypes in our $\alpha B$-crystallin homozygous null larvae. The reason for the discrepancy in our present CRISPR work and a past study (Mishra et al., 2018) is unclear. Our mass spectrometry data indicated a loss of $\alpha \mathrm{Ba}$ - and $\alpha \mathrm{Bb}$-crystallin in our null adult lenses, so our lack of a phenotype does not appear to be the result of residual protein. We did detect some residual peptides from these crystallins during our analysis, but these were attributed to carry over on the chromatography column during the highly sensitive parallel reaction monitoring analysis. It is possible that the difference in results is due to variation in the background genetics of the zebrafish lines used. We show in this study that different populations of wildtype fish can produce larvae with different lengths and lens diameters (Fig 5), and we see variable, low levels of lens defects in wildtype larvae between breedings. This variation could contribute to differences between studies.

The variety of approaches used to produce $\alpha A$-crystallin mutants in this study allows us to compare their utility for studying resulting phenotypes. The quickest way to screen genes for their role in 
development is to directly examine larvae injected at the zygote state. There is good evidence that this approach is effective when injecting a mix of four gRNAs (Wu et al., 2018). In our own hands we found this approach effective when targeting genes already known to play an essential role in lens development. For example, injection of a four gRNA mix (pgRNA) targeting the transcription factor foxe3 closely replicated phenotypes reported in a stable zebrafish null line (Supplemental Fig 1; (Krall \& Lachke, 2018)). However, when targeting cryaa this approach did not produce similar levels of phenotypes seen in our null line (Fig 4). The proportion of each defect differed between the two approaches, and the levels of some defects also differed between 3 and $4 \mathrm{dpf}$. These variations in phenotype could be due to the mosaic nature of gRNA injected larvae, in which some lens cells contain mutant cryaa alleles and others contain wildtype alleles. The expression of $\alpha A$-crystallin in unaffected cells may be enough to prevent the defects seen in our null line. We previously showed that adult zebrafish lenses produce less $\alpha A$-crystallin than mammalian lenses (Posner et al., 2008), and our past qPCR and single cell RNA-Seq data suggest that lens cryaa expression through $5 \mathrm{dpf}$ is relatively low as well (Posner et al., 2017; Farnsworth, Posner \& Miller, 2021). Since the complete loss of $\alpha A$-crystallin in our cryaa null line only led to visible defects in $60 \%$ of larvae, the expression of reduced amounts in our injected embryos may be sufficient to alter the phenotype. It is also possible that differences are simply due to the stochastic nature of phenotype development. Considering the dynamic changes occurring in the zebrafish lens between 3 and $4 \mathrm{dpf}$ it is best to quantify phenotypes for each day separately in future studies.

Because our initial cryaa null line generated with a single gRNA and containing a frame shift mutation stopped breeding, we took the opportunity to generate a second null line with a large deletion removing the proximal promoter region and start codon. Both lines generated similar lens defects, reinforcing the conclusion that these defects resulted from the loss of $\alpha A$-crystallin and not off-target effects. There are two other benefits to generating mutant knockout alleles by deletion. First, these deletion alleles are simpler to screen, as they are identifiable by PCR without subsequent sequencing. Second, deletion of the promoter and start codon reduces the chance of possible genetic compensation after nonsense mediated mRNA decay (El-Brolosy et al., 2019). The loss of the targeted gene's mRNA can also be monitored by qPCR (Fig 7). Our two $\alpha B$-crystallin null lines were produced with single gRNAs and frame shift mutations. While our proteomics work confirmed loss of each protein in our null adult fish lenses, qPCR showed reduction in cryabb mRNA in the cryabb null line, but no reduction in cryaba mRNA in the cryaba null line. This difference may reflect the unpredictability of non-sense mediated decay, and shows that mRNA levels do not necessarily reflect eventual protein levels. It is also possible that this difference in mRNA levels reflects primer location, as our cryaba qPCR primers annealed within exon 1, just downstream of the gRNA target site, while our cryabb primers annealed to the $5^{\prime}$ UTR.

Several key questions remain unanswered in this study. It is unclear how the loss of $\alpha A$-crystallin leads to the visual defects observed by DIC microscopy. Lenses from mutant and knockout $\alpha$-crystallin mice have been analyzed by proteomics and RNA-Seq to identify changes in global gene expression (Andley et al., 2013, 2018). A similar approach would be valuable with our zebrafish null lines. We have only presented data through $7 \mathrm{dpf}$. It will be interesting to see how $\alpha \mathrm{A}$-crystallin loss impacts lens clarity and optics as fish age. While we know that both $\alpha B$-crystallin genes are expressed in the adult lens, we 
467 do not know at what age this expression begins, and how $\alpha \mathrm{B}$-crystallin loss may impact lenses as they

468 age. This question is particularly interesting as cryaba is lens specific in adults while cryabb is expressed 469 broadly, suggesting an ontogenetic shift in the function of these genes and their proteins. Why cryaba 470 is expressed outside the lens in early development, and whether it or cryabb plays an important 471 developmental role in those extralenticular tissues, is also unknown. Answers to these questions would 472 add to the understanding of why these small heat shock protein genes were co-opted as key players 473 during vertebrate lens evolution.

478 We would like to thank the many members of the zebrafish research community who were helpful 479 with technical suggestions. The plasmid-free protocol used to generate gRNAs was shared with us by 480 Dr. Cody Smith at the University of Notre Dame. Dr. Jennifer Phillips at the University of Oregon first 481 suggested our double gRNA deletion approach for generating our cryaa mutant. Caitlin Puff 482 contributed to the measurements of larval body length and lens diameters. This work was supported 483 by the NIH National Eye Institute (R15 EY13535) to MP, by the Provost Office at Ashland University's 484 (AU) student research grant program and by the AU Choose Ohio First program that provided summer 485 research support to KM. Mass spectrometric analysis was supported by the NIH National Institute (P30 486 EY010572. 
489

490

491

492

493

494

495

496

497

498

499

500

501

502

503

504

505

506

507

508

509

510

511

512

513

514

515

516

517

518

519

520

521

\section{Citations}

Andley UP, Malone JP, Hamilton PD, Ravi N, Townsend RR. 2013. Comparative Proteomic Analysis Identifies Age-Dependent Increases in the Abundance of Specific Proteins after Deletion of the Small Heat Shock Proteins $\alpha A-$ and $\alpha B-C r y s t a l l i n$. Biochemistry 52:2933-2948. DOI: 10.1021/bi400180d.

Andley UP, Tycksen E, McGlasson-Naumann BN, Hamilton PD. 2018. Probing the changes in gene expression due to $\alpha$-crystallin mutations in mouse models of hereditary human cataract. PLoS ONE 13:e0190817-18. DOI: 10.1371/journal.pone.0190817.

Bova MP, Yaron O, Huang Q, Ding LL, Haley DA, Stewart PL, Horwitz J. 1999. Mutation R120G in alphaBcrystallin, which is linked to a desmin-related myopathy, results in an irregular structure and defective chaperone-like function. Proceedings of the National Academy of Sciences of the United States of America 96:6137-6142.

Boyle DL, Takemoto L. 2000. A possible role for alpha-crystallins in lens epithelial cell differentiation. Molecular vision 6:63-71.

Brady JP, Garland D, Duglas-Tabor Y, Robison WG, Groome A, Wawrousek EF. 1997. Targeted disruption of the mouse alpha A-crystallin gene induces cataract and cytoplasmic inclusion bodies containing the small heat shock protein alpha B-crystallin. Proceedings of the National Academy of Sciences of the United States of America 94:884-889.

Brady JP, Garland DL, Green DE, Tamm ER, Giblin FJ, Wawrousek EF. 2001. AlphaB-crystallin in lens development and muscle integrity: a gene knockout approach. Investigative ophthalmology \& visual science 42:2924-2934.

Bustin SA, Benes V, Garson JA, Hellemans J, Huggett J, Kubista M, Mueller R, Nolan T, Pfaffl MW, Shipley GL, Vandesompele J, Wittwer CT. 2009. The MIQE guidelines: minimum information for publication of quantitative real-time PCR experiments.

Collery RF, Veth KN, Dubis AM, Carroll J, Link BA. 2014. Rapid, Accurate, and Non-Invasive Measurement of Zebrafish Axial Length and Other Eye Dimensions Using SD-OCT Allows Longitudinal Analysis of Myopia and Emmetropization. PLOS ONE 9:e110699. DOI: 10.1371/journal.pone.0110699.

Dahlman JM, Margot KL, Ding L, Horwitz J, Posner M. 2005. Zebrafish alpha-crystallins: protein structure and chaperone-like activity compared to their mammalian orthologs. Molecular vision 11:88-96. 
El-Brolosy MA, Kontarakis Z, Rossi A, Kuenne C, Günther S, Fukuda N, Kikhi K, Boezio GLM, Takacs CM, Lai S-L, Fukuda R, Gerri C, Giraldez AJ, Stainier DYR. 2019. Genetic compensation triggered by mutant mRNA degradation. Nature:1-26. DOI: 10.1038/s41586-019-1064-z.

Farnsworth D, Posner M, Miller A. 2021. Single cell transcriptomics of the developing zebrafish lens and identification of putative controllers of lens development. Experimental Eye Research:108535. DOI: 10.1016/j.exer.2021.108535.

Greiling TMS, Aose M, Clark JI. 2010. Cell fate and differentiation of the developing ocular lens. Investigative ophthalmology \& visual science 51:1540-1546. DOI: 10.1167/iovs.09-4388.

Greiling TMS, Houck SA, Clark JI. 2009. The zebrafish lens proteome during development and aging. Molecular vision 15:2313-2325.

Hinaux H, Blin M, Fumey J, Legendre L, Heuzé A, Casane D, Rétaux S. 2014. Lens defects in Astyanax mexicanusCavefish: Evolution of crystallins and a role for alphaA-crystallin. Developmental neurobiology:n/a-n/a. DOI: 10.1002/dneu.22239.

Horwitz J. 1992. Alpha-crystallin can function as a molecular chaperone. Proceedings of the National Academy of Sciences of the United States of America 89:10449-10453.

Koteiche HA, Claxton DP, Mishra S, Stein RA, McDonald ET, McHaourab HS. 2015. Species-Specific Structural and Functional Divergence of $\alpha$-Crystallins: Zebrafish $\alpha B a-$ and Rodent $\alpha A$ ins-Crystallin Encode Activated Chaperones. Biochemistry 54:5949-5958. DOI: 10.1021/acs.biochem.5b00678.

Krall M, Lachke SA. 2018. A zebrafish model of foxe3 deficiency demonstrates lens and eye defects with dysregulation of key genes involved in cataract formation in humans. Human genetics 137:315-328. DOI: 10.1007/s00439-018-1884-1.

Mishra S, Wu S-Y, Fuller AW, Wang Z, Rose KL, Schey KL, McHaourab HS. 2018. Loss of aB-crystallin function in zebrafish reveals critical roles in the development of the lens and stress resistance of the heart. The Journal of biological chemistry 293:740-753. DOI: 10.1074/jbc.m117.808634.

Pino LK, Searle BC, Bollinger JG, Nunn B, MacLean B, MacCoss MJ. 2020. The Skyline ecosystem: Informatics for quantitative mass spectrometry proteomics. Mass Spectrometry Reviews 39:229244. DOI: 10.1002/mas.21540.

Posner M, Hawke M, Lacava C, Prince CJ, Bellanco NR, Corbin RW. 2008. A proteome map of the zebrafish (Danio rerio) lens reveals similarities between zebrafish and mammalian crystallin expression. Molecular vision 14:806-814.

Posner M, Murray KL, McDonald MS, Eighinger H, Andrew B, Drossman A, Haley Z, Nussbaum J, David LL, Lampi KJ. 2017. The zebrafish as a model system for analyzing mammalian and native $\alpha$-crystallin promoter function. PeerJ 5:e4093-27. DOI: 10.7717/peerj.4093. 
Posner M, Skiba J, Brown M, Liang JO, Nussbaum J, Prior H. 2013. Loss of the small heat shock protein $\alpha \mathrm{A}-$ crystallin does not lead to detectable defects in early zebrafish lens development. Experimental Eye Research. DOI: 10.1016/j.exer.2013.09.007.

R Core Team. 2021.R: A language and environment for statistical computing. R Foundation for Statistical Computing, Vienna, Austria. URL https://www.R-project.org/

R Studio Team. 2020. RStudio: Integrated Development for R. RStudio, PBC, Boston, MA URL http://www.rstudio.com/

Smith AA, Wyatt K, Vacha J, Vihtelic TS, Zigler JS, Wistow GJ, Posner M. 2006. Gene duplication and separation of functions in alphaB-crystallin from zebrafish (Danio rerio). The FEBS journal 273:481490. DOI: $10.1111 / \mathrm{j} .1742-4658.2005 .05080 . x$.

Srinivasan AN, Nagineni CN, Bhat SP. 1992. alpha A-crystallin is expressed in non-ocular tissues. The Journal of biological chemistry 267:23337-23341.

Vorontsova I, Gehring I, Hall JE, Schilling TF. 2018. Aqp0a Regulates Suture Stability in the Zebrafish Lens. Investigative ophthalmology \& visual science 59:2869-11. DOI: 10.1167/iovs.18-24044.

Wang K, Vorontsova I, Hoshino M, Uesugi K, Yagi N, Hall JE, Schilling TF, Pierscionek BK. 2020. Optical development in the zebrafish eye lens. FASEB journal : official publication of the Federation of American Societies for Experimental Biology 95:399-11. DOI: 10.1096/fj.201902607r.

Wu RS, Lam II, Clay H, Duong DN, Deo RC, Coughlin SR. 2018. A Rapid Method for Directed Gene Knockout for Screening in G0 Zebrafish. Developmental Cell 46:112-125.e4. DOI: 10.1016/j.devcel.2018.06.003.

Zou P, Wu S-Y, Koteiche HA, Mishra S, Levic DS, Knapik E, Chen W, McHaourab HS. 2015. A conserved role of $\alpha \mathrm{A}$-crystallin in the development of the zebrafish embryonic lens. Experimental Eye Research 138:104-113. DOI: 10.1016/j.exer.2015.07.001. 


\section{Figure 1}

A
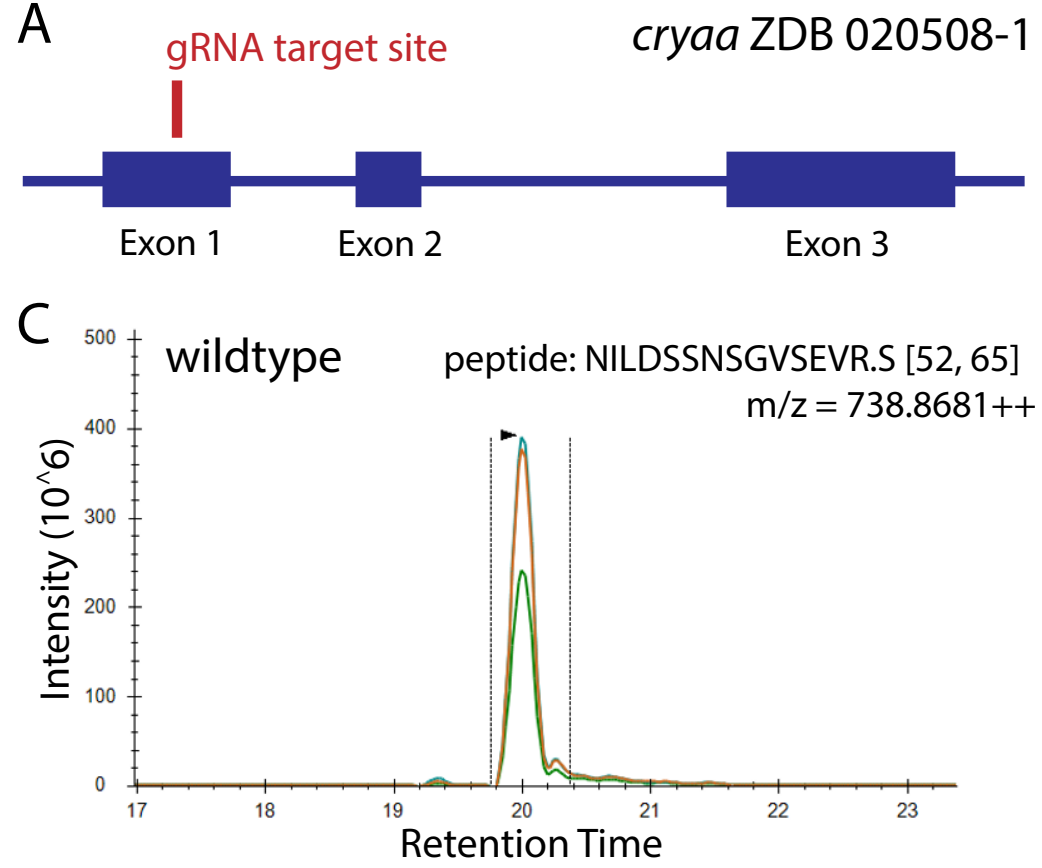

B

Residue $\begin{array}{lllllllllll}23 & 24 & 25 & 26 & 27 & 28 & 29 & 30 & 31 & 32 & 33\end{array}$ WT TTTGGAGAAGGCCTGTTCGATTATGACCTATTC $\begin{array}{llllllllllllllllll} & F & G & E & G & L & F & D & Y & D & L & F\end{array}$ Mutant TTTGGAGAAGGCC-----GATTATGACCTATTC F $\quad G \quad E \quad G \quad R \quad L \quad * \quad P \quad I$

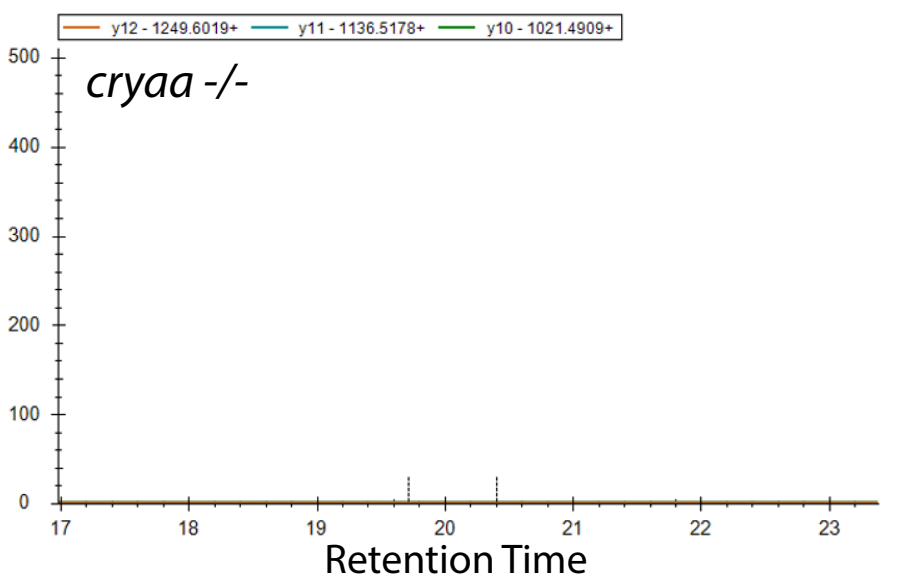

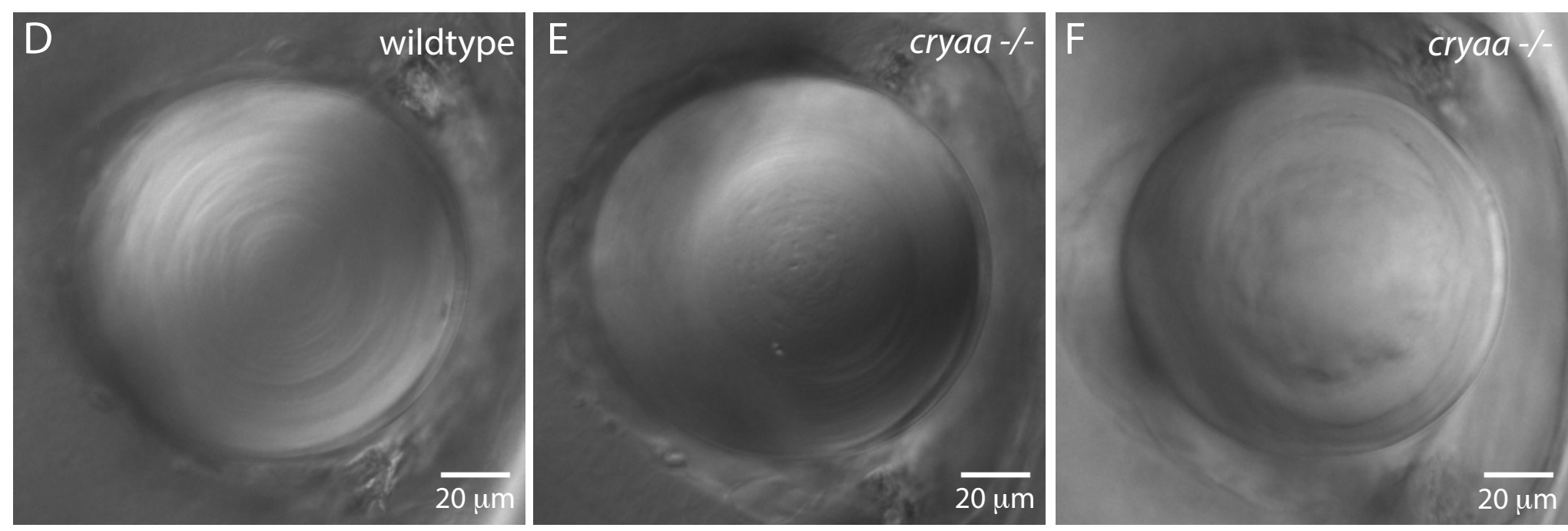

Figure 1. cryaa null mutant. Produced with a single gRNA to generate a five basepair deletion and frame shift mutation in exon 1, with relative position noted by red line (A). Injected embryos were outcrossed to wildtype fish to identify heterozygote mutants, with a five basepair deletion allele identified that leads to an early stop codon after amino acid 28 (B). Incrossed heterozygotes were used to generate a homozygous null line, which was bred to assess the effects of cryaa loss. Mass spectrometry confirmed that embryos generated by incrossing this null line produced no detectable alpha A crystallin protein (C). Parallel reaction monitoring of the 3 major fragment ions of the +3 charge state of cryaa peptide 52-65 from the digest of wildtype lenses showed coelution of its three major fragment ions on the left and no corresponding peaks in the digest from KO lenses on the right (C). Compared to wildtype lenses at $3 \mathrm{dpf}(\mathrm{D})$, cryaa null embryos showed various defects such as roughness in the primary fiber cell region (E) and a general disorganization of central fiber cells (F). Lenses are from $3 \mathrm{dpf}$ embryos, imaged using DIC optics and arranged with retina to the left. Scale bars are 20 microns. 


\section{Figure 2}
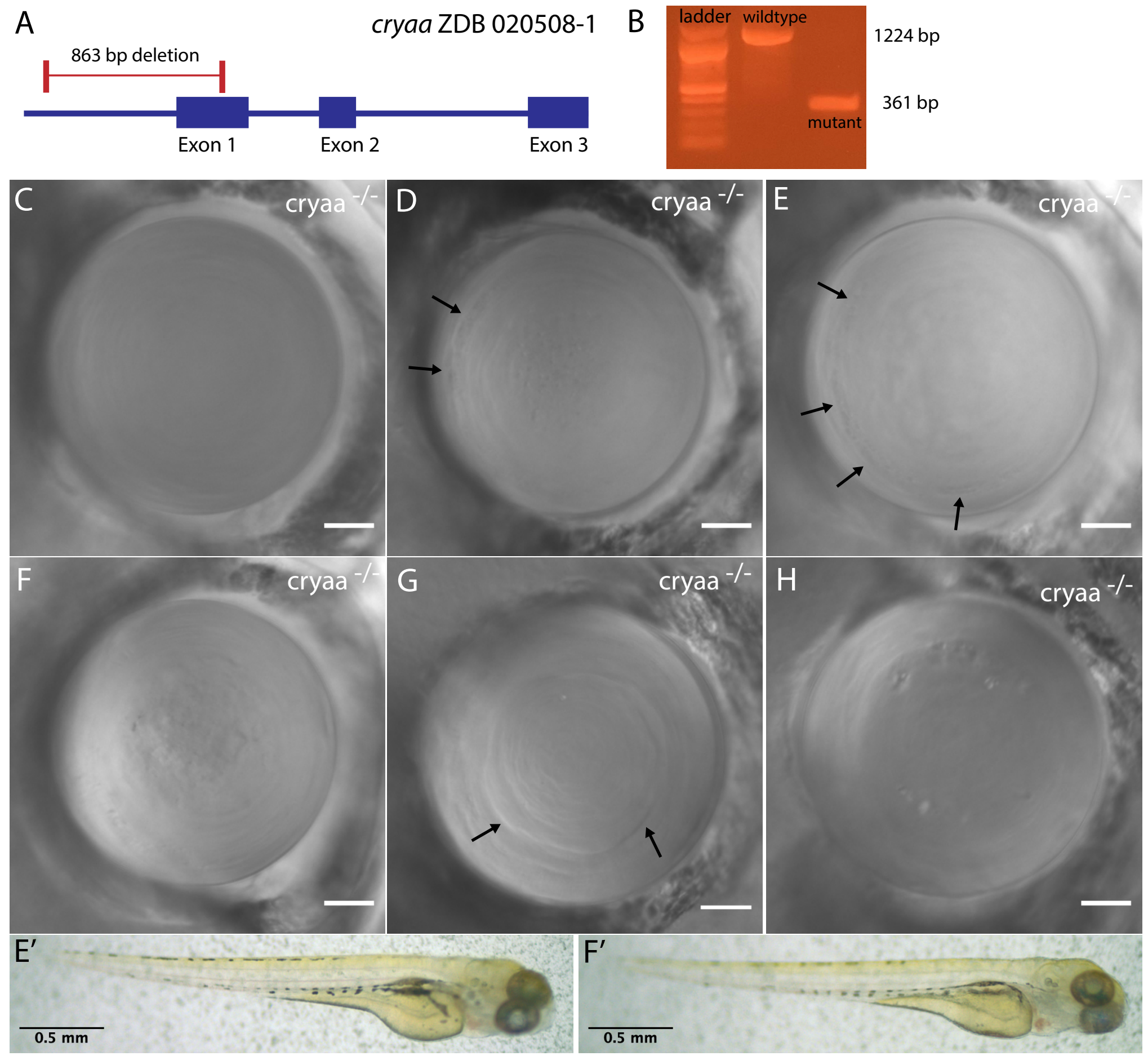

Figure 2. Second cryaa null mutant line generated by deleting start codon and proximal promoter region produced variable lens phenotypes. Two gRNAs were designed to remove approximately 860 basepairs of the cryaa gene (A). This large deletion could be easily identified using PCR amplification with primers flanking the gRNA target regions (B). Some cryaa null embryos showed visually normal lenses by DIC imaging (C). Typical phenotypes in abnormal lenses included roughness in central primary fiber cells (D), and general disorganization of central fiber cells (E), as seen in our single gRNA null mutant (Figure 1). Gaps or pits between peripheral fiber cells were also common ( $D$ and E: arrows). Some lenses combined several of these phenotypes (F). We also saw lenses with severe boundaries between fiber cells (G: arrows) and pitting (H). Lenses shown are either 3 or $4 \mathrm{dpf}$ and arranged with retina to the left. Scale bars are 20 microns. Matching embryos for lenses $E$ and $F$ are shown to indicate lack of general morhological defects ( $E^{\prime}$ and $\left.F^{\prime}\right)$. 


\section{Figure 3}
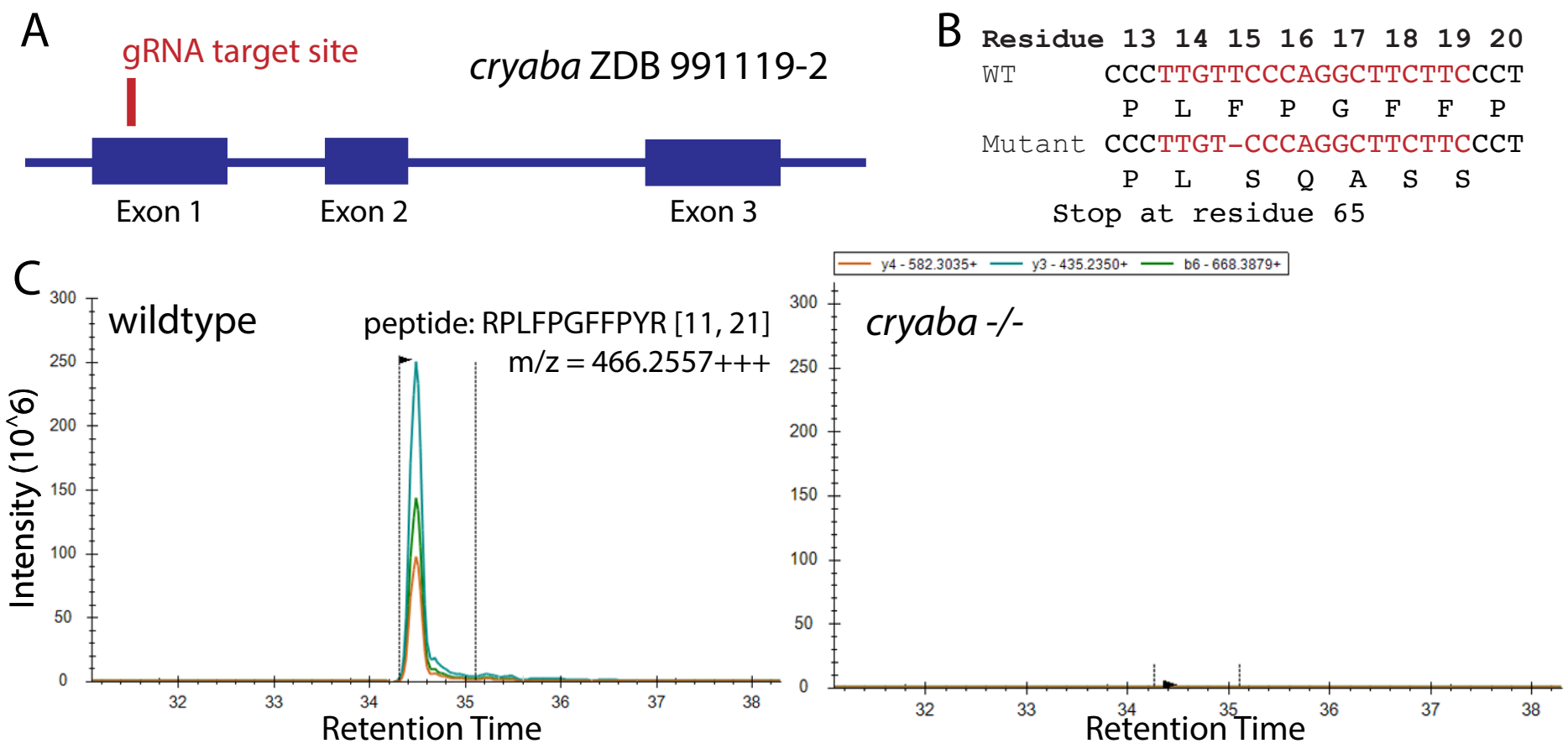

$y 4-582.3035+-y 3-435.2350+-b 6-668.3879+$
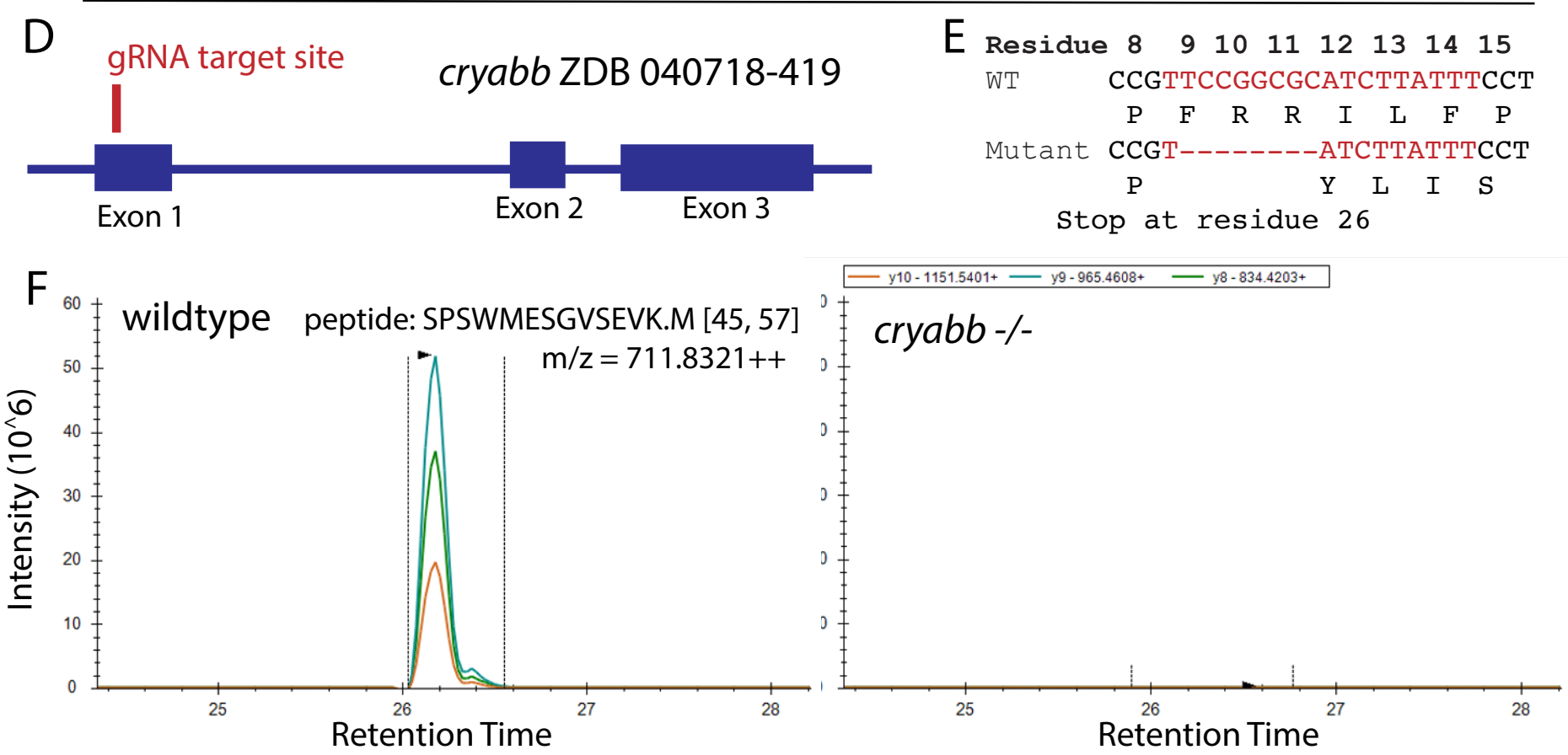

Figure 3. Production of cryaba and cryabb frameshift mutants. Single gRNAs were designed to target the first exons of the zebrafish cryaba (A) and cryabb (D) genes. After injection into wildtype zygotes founders were outcrossed to wildtype fish and resulting heterozygotes with deletions that caused frameshift mutations leading to early stop codons were detected ( $B$ and $E$ ). Mass spectrometry analysis of adult lenses from mutant null lines confirmed the loss of protein coded by each gene. Parallel reaction monitoring of the +3 charge state of $\alpha B a-c r y s t a l l i n$ tryptic peptide 11-21 from the digest of wildtype lenses detected coelution of its three major fragment ions (left) and these were not detectable in cryaba null adult lenses (C). Similarly, the +2 charge state of $\alpha B b$-crystallin tryptic peptide $45-57$ from the digest of wildtype lenses detected coelution of its three major fragment ions (left) and these were missing in digests from cryabb null adult lenses on the right $(F)$. 


\section{Figure 4}

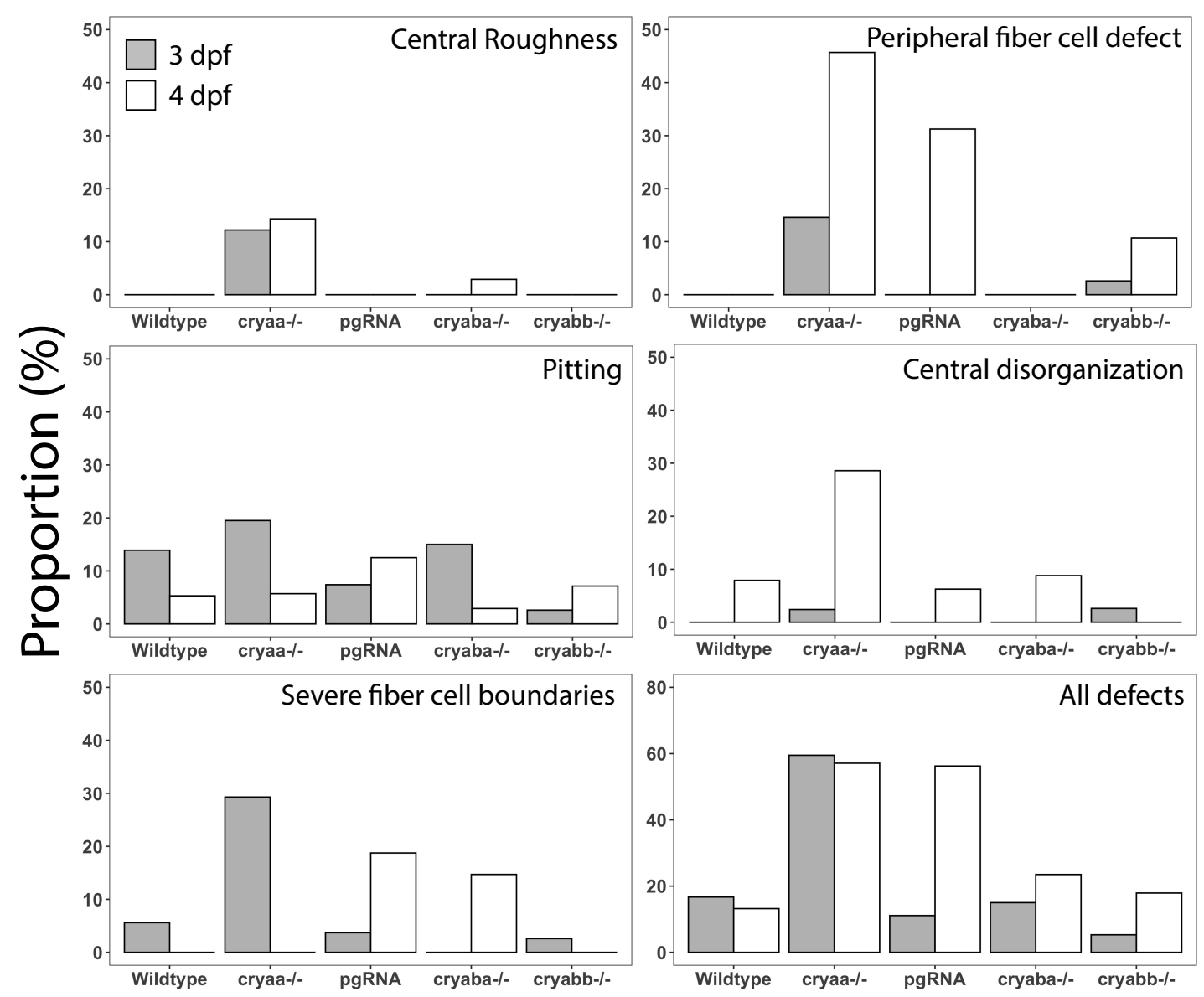

Figure 4. Prevalence of different lens abnormalities in wildtype, $\alpha$-crystallin knockout and cryaa gRNA injected larvae at 3 and 4 dpf. Each graph shows the proportion of larvae with that defect type. Larvae examined at 3 and $4 \mathrm{dpf}$, respectively were wildtype $(n=36 / 38)$, offspring of homozygous null mutants for cryaa $(n=41 / 35)$, cryaba $(n=40 / 34)$ and cryabb $(n=38 / 28)$, and embryos injected with a four-gRNA mix targeting the cryaa gene (pgRNA; $n=27 / 16)$. 
Figure 5
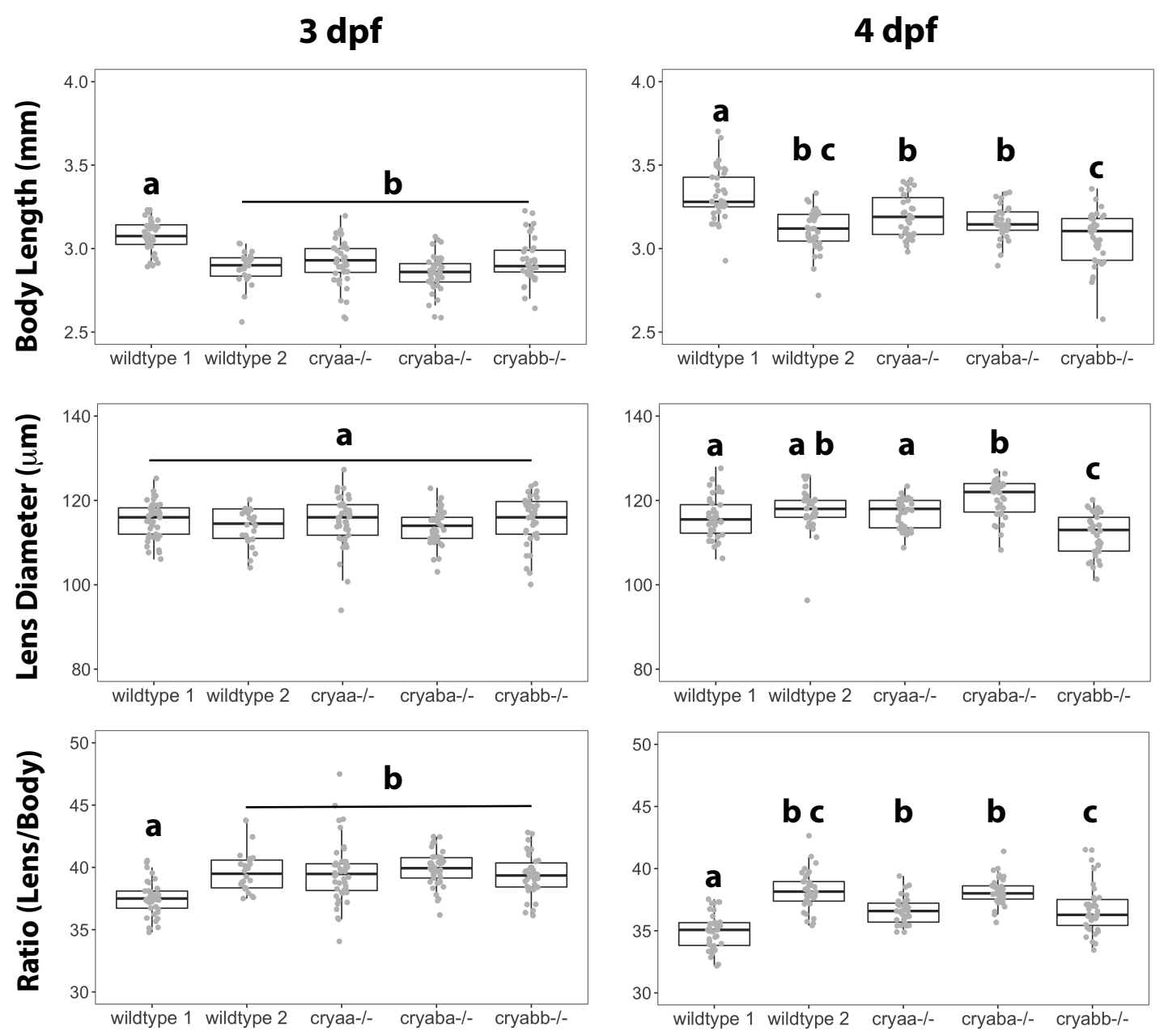

Figure 5. Comparison of lens diameters and body lengths between wildtype and $\alpha$-crystallin knockout embryos. Box and whisker plots show measurements at 3 and 4 days post fertilization. Analysis of variance with Tukey post test was used to identify statistically significant differences between groups. Letters indicate statistical groups within each panel. 


\section{Figure 6}

\section{3 dpf}
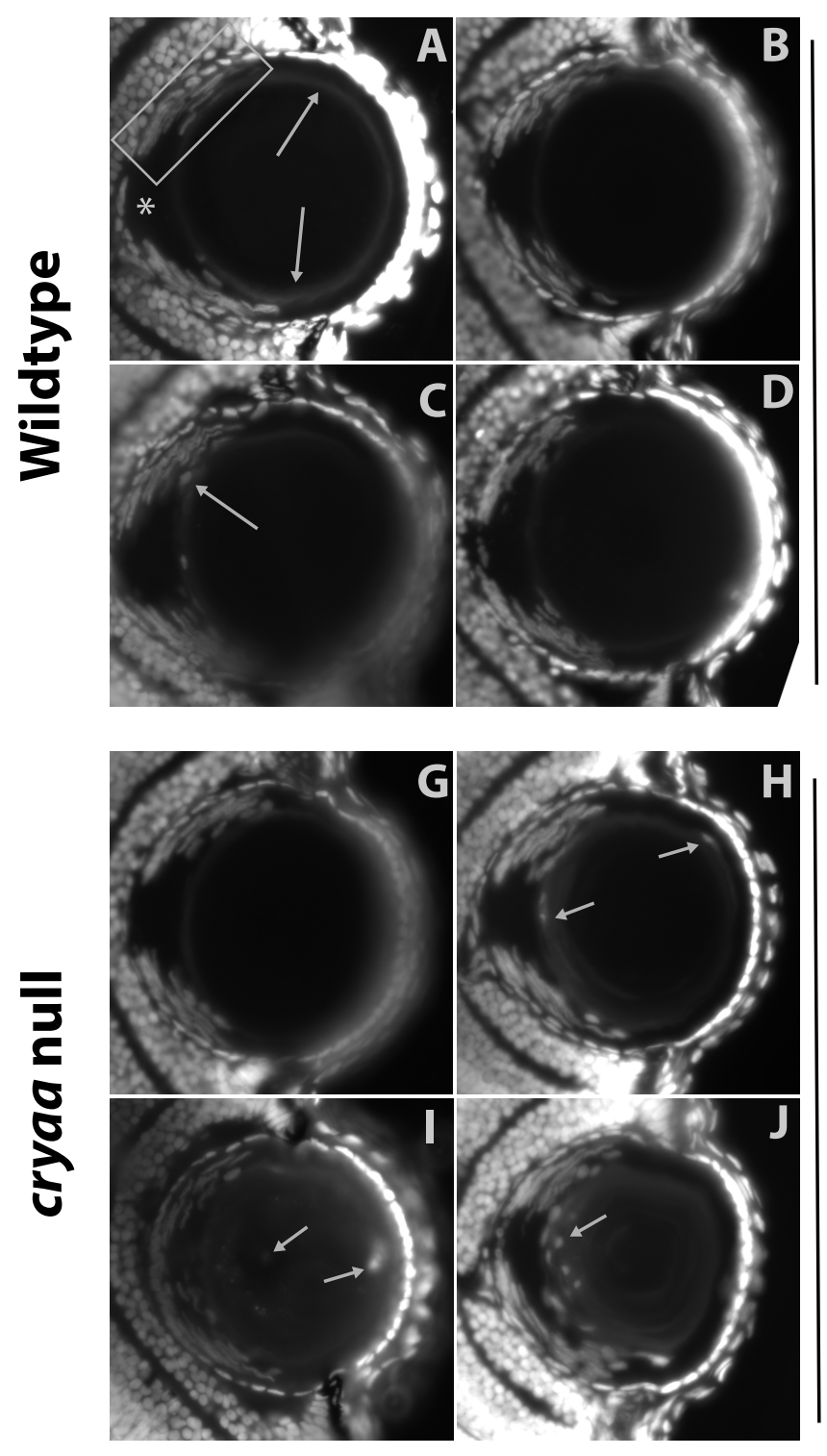

4 dpf
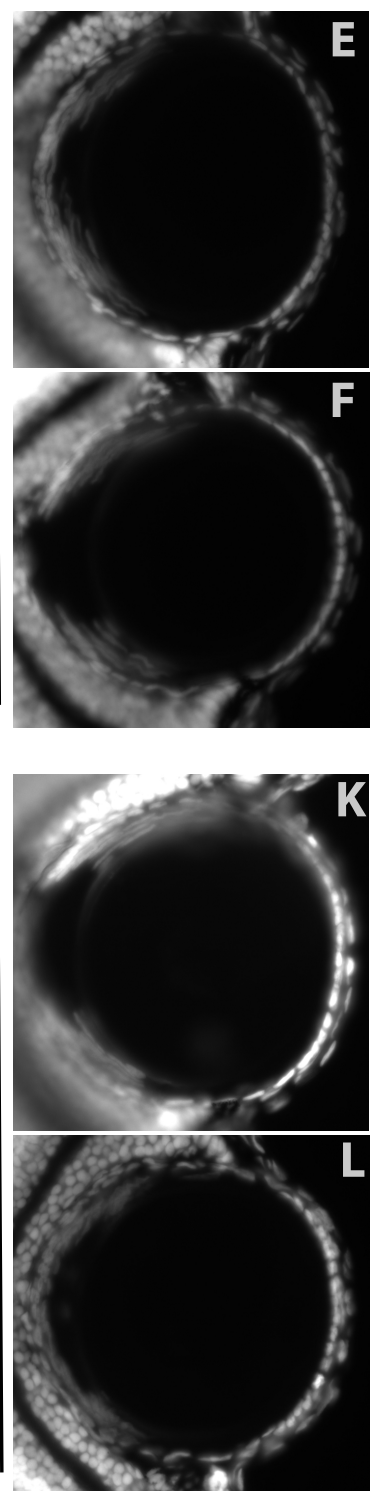
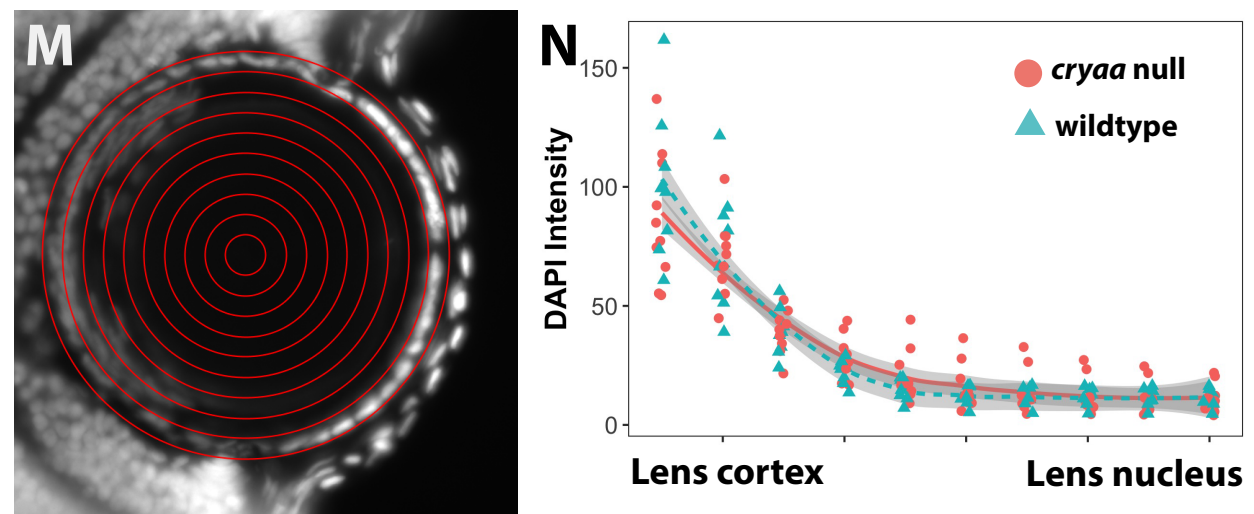

Figure 6. Cryosectioned lenses at 3 and $\mathbf{4} \mathbf{d p f}$ stained with DAPI to assess clearance of fiber cell nuclei. Four representative lenses are shown for wildtype (A-D) and the cryaa null line (G-J) at $3 \mathrm{dpf}$, and two representative lenses at $4 \mathrm{dpf}(\mathrm{E}-\mathrm{F} ; \mathrm{K}-\mathrm{L})$. Most images were taken at 200X total magnification, with some taken at $100 \mathrm{X}$ to capture more lens cell nuclei in one focal plane. Retina is oriented to the left in each image, with cornea to the right. The four images at : $\mathrm{dpf}$ for each genotype demonstrate the range of phenotypes found, with the top left panel the most normal and bottom right the most abnormal. Rectangle in panel A highlights one of two regions of flattened, extended fiber cell nuclei at retinal side of the lens, separated by a nucleus free zone at *. Arrows indicate details described in the results section. Concentric circles were used to measure average pixel density of DAPI staining across the lens (see $M$ as an example). While some cryaa null lenses showed higher DAPI intensity in inner areas of the lens at $3 \mathrm{dpf}(\mathrm{N})$, these differences were not statistically significant (Mann-Whitney U test). 


\section{Figure 7}

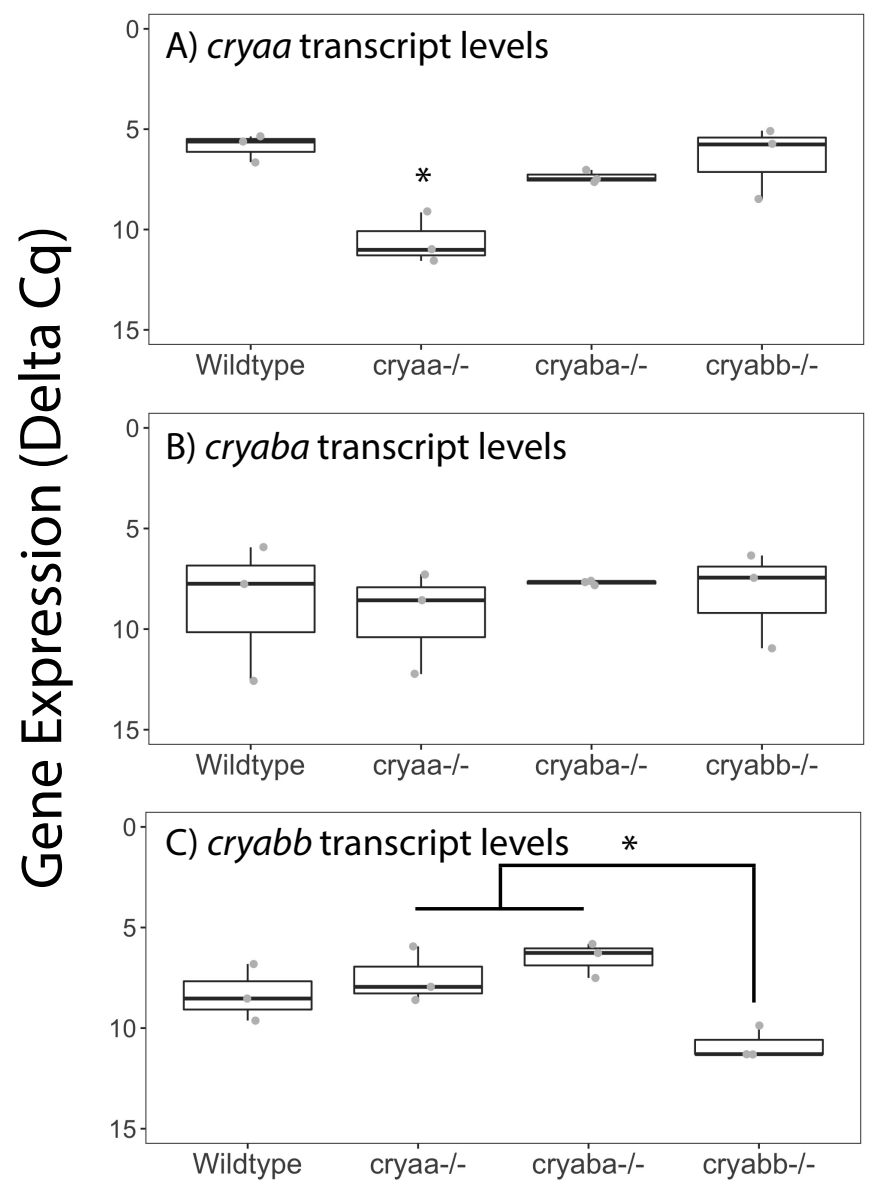

Figure 7. Expression of each $\alpha$-crystallin gene assayed by qPCR in whole bodies of wildtype and mutant larvae at 7 dpf. Box and whisker plots show delta Cq values generated with primers for cryaa (A), cryaba (B) and cryabb (C) in three biological replicates of the genotypes indicated on the X-axes. Y-axes are inverted as lower delta $\mathrm{Cq}$ values indicate greater expression. Asterisks indicate statistically significant differences based on ANOVA with Tukey post test ( $p$-value <0.05). 